\title{
Transesophageal Echocardiographic Findings of Quadricuspid Aortic Valve
}

\author{
Lai Cha-Po, M.D., Samon Koyanagi, M.D., \\ Junichi Sadoshima, M.D., Akira Takeshita, M.D., \\ and Kouichi Tokunaga, M.D.*
}

\begin{abstract}
SUMMARY
We report a case of a 40-year-old man who had a quadricuspid aortic valve associated with aortic regurgitation. The anomaly was revealed by transesophageal echocardiography (TEE), and confirmed by cardiac surgery. TEE is a useful noninvasive method for identifying the quadricuspid aortic valve.
\end{abstract}

\section{Key Words :}

Transesophageal echocardiography Aortic regurgitation Quadricuspid aortic valve

F the various congenital abnormalities affecting the aortic valves, the quadricuspid aortic valve is a very rare anomaly, far less common than valves with either 1 or 2 cusps; most of these are discovered at autopsy. ${ }^{1}$ Only a small number of preoperatively diagnosed cases have been reported in the world literature, all of these having been demonstrated by aortography, except 1 case in which Herman diagnosed a quadricuspid aortic valve by transthoracic echocardiography. ${ }^{2)}$ Here, we report the case of a patient with aortic regurgitation, in whom transesophageal echocardiography (TEE) revealed a quadricuspid aortic valve.

\section{CASE REPORT}

A 40-year-old man was referred to our hospital on January 17, 1990, because of exertional dyspnea and aortic regurgitation. Cardiac murmur was first discovered when he was 20 years old. There was no history of rheumatic fever. Physical examination revealed a well developed patient whose blood

From the Research Institute of Angiocardiology and Cardiovascular Clinic, and *Division of Cardiovascular Surgery, Faculty of Medicine, Kyushu University, Fukuoka, Japan.

Address for correspondence: Samon Koyanagi, M.D., Research Institute of Angiocardiology and Cardiovascular Clinic, Faculty of Medicine, Kyushu University, 3-1-1 Maidashi, Higashi-ku, Fukuoka 812, Japan.

Received for publication February 9, 1991.

Accepted March 8, 1991. 
pressure was $108 / 44 \mathrm{mmHg}$ and pulse rate was 58 beats/min. There was a grade $3 / 6$ systolic ejection murmur and a grade $3 / 6$ high pitched diastolic murmur over the left sternal border. An electrocardiogram showed sinus rhythm, left axis deviation and left ventricular hypertrophy with an amplitude of $7.0 \mathrm{mV}$ in $\mathrm{SV}_{1}+\mathrm{RV}_{5}$. Roentgenographic examination of the chest revealed mild cardiomegaly with a cardiothoracic ratio of $54 \%$.

Transthoracic two-dimensional echocardiography (TTE) showed that the left ventricle $(\mathrm{LV})$ was slightly dilated (end-diastolic left ventricular diameter was $53 \mathrm{~mm}$ ) with decreased ejection fraction $(\mathrm{EF}=57 \%)$ and mild LV hypertrophy. Flow imaging Doppler echocardiography revealed severe aortic regurgitation. Between the left coronary cusp and the noncoronary cusp of the aortic valve an accessory cusp-like echo was obtained, but not clearly. TEE showed a clear four-cusped aortic valve (3 equal and 1 small). They are in incomplete juxtaposition in diastole, and the left coronary ostium is located near the commissure of the left coronary cusp and the accessory cusp (Fig. 1). An aortic regurgitation jet was observed at the incomplete closure of the aortic valve. Aortogram could not demonstrate a four-cusped aortic valve, but did show grade $3 / 4$ aortic regurgitation.

The patient underwent surgery. There were four aortic cusps (3 equal sized and 1 small cusp) with four commissures. The left cusp was divided unequally into 2 parts with one part smaller than the others. All four cusps

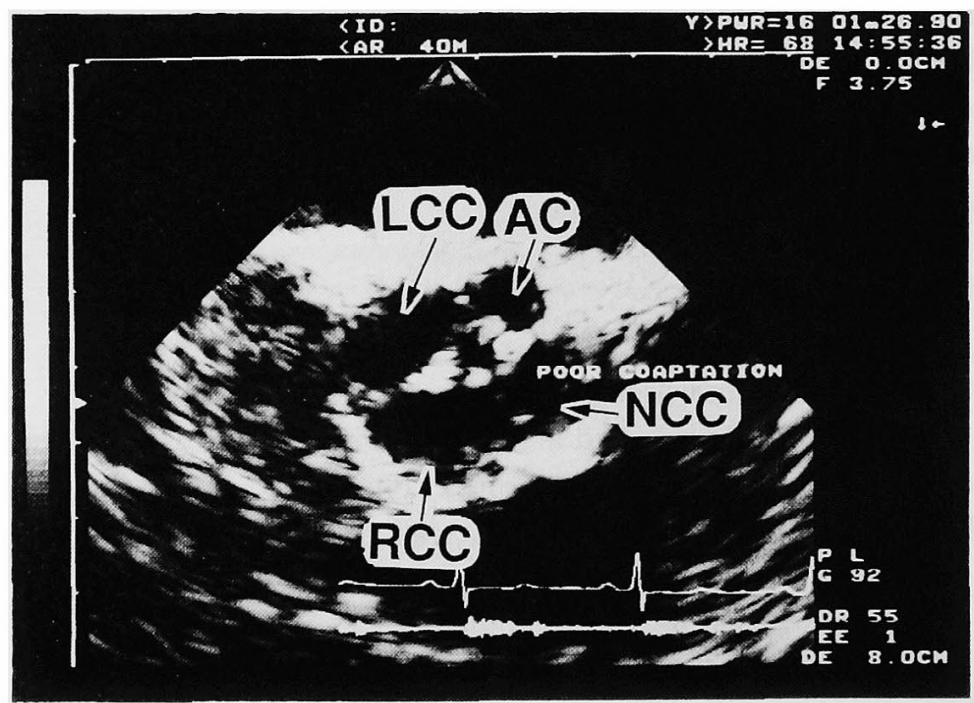

Fig. 1. Transesophageal echocardiogram of quadricuspid aortic valve. Four cusps with four commissures, and poor coaptation of the aortic leaflets. $\mathrm{RGC}=$ right coronary cusp; $\mathbf{L G C}=$ left coronary cusp; $\mathrm{NCG}=$ noncoronary cusp; $\mathrm{AC}=$ accessory cusp. 


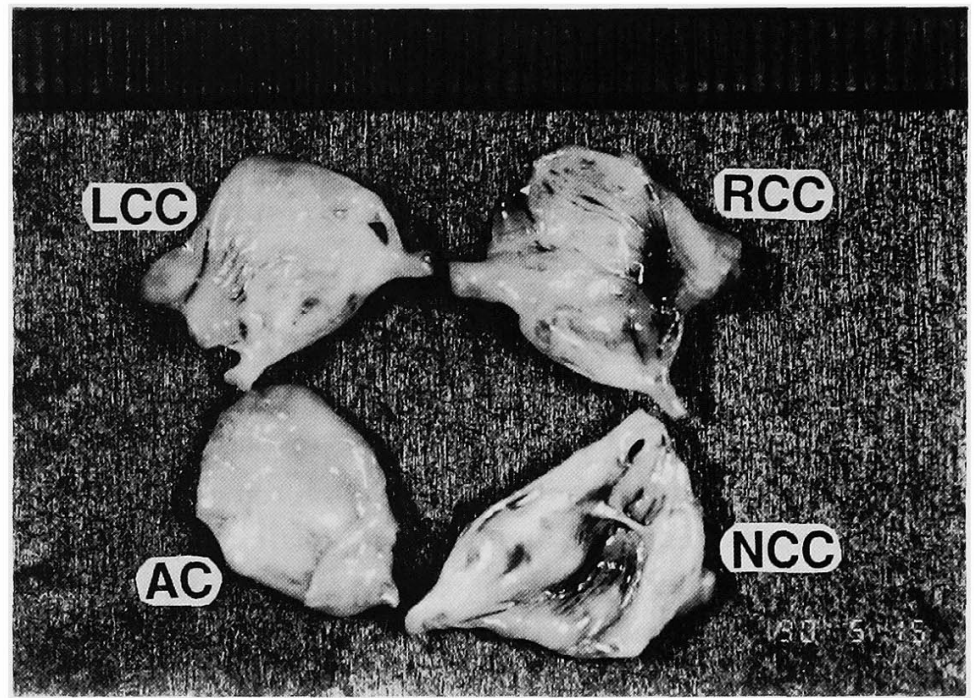

Fig. 2. Gross appearance of the resected specimen showing four cusps, in which the noncoronary cusp was smaller than the others. All four cusps were mildly thickened and retracted at the free edges. $R C G=$ right coronary cusp; $\mathrm{LGC}=$ left coronary cusp; $\mathrm{NCC}=$ noncoronary cusp; $\mathrm{AC}=$ accessory cusp.

were mildly thickened and retracted at the free edges (Fig. 2). The right coronary ostium was normally situated, but the left one was just beneath the commissure between the separated left coronary cusps.

\section{Discussion}

A congenital four-cusped aortic valve is a very rare malformation which may arise from the anomalous septation of the truncus arteriosus, or from the interpolation of an extra pad in the common trunk. Balington, in 1862, was the first to report the anomaly at autopsy. Simonds, in a review of the literature in 1923, reported that the incidence of an isolated quadricuspid aortic valve was about $0.008 \%$ ( 2 cases found in 25,666 autopsies). ${ }^{1}$ ) To the best of our knowledge, a review of the previous reports showed 17 cases, ${ }^{3)}$ including our own case, having had surgery for symptomatic aortic valve disease. In only 9 of these cases was there a preoperative clinical diagnosis, most of these having been diagnosed by aortography, except one which was diagnosed by TTE. ${ }^{2)}$ Our case may be the first in which a quadricuspid aortic valve was identified by TEE.

According to the size of the four aortic valve cusps, Hurwitz and Roberts classified these patterns into 7 anatomical variations. ${ }^{4)}$ The pattern of 3 equal-sized cusps and 1 small cusp, as observed in our case, has been re- 
ported to occur most frequently. In this pattern, the accessory cusp was situated between the right cusp and the noncoronary one in most cases. In our case, the left coronary cusp was divided into 2 parts with the commissure just at the left coronary ostium. These findings were confirmed at surgery.

Amioka reported that the incidence of aortic regurgitation in the quadricuspid aortic valve is about $59 \% .^{51}$

There are some reports indicating displacement of the coronary orifice associated with a quadricuspid aortic valve. ${ }^{61,7)}$ There was 1 case who died as a result of an obstruction of the coronary orifice caused by a prosthetic aortic valve. In our case, the left coronary ostium was located abnormally just beneath the commissure of the separated left coronary cusps.

It is possible to diagnose the quadricuspid aortic valve by TTE, but the echocardiogram may sometimes not be clear enough. In our case, a clear echocardiogram of the quadricuspid aortic valve and the relationship between the cusps and the orifice of the coronary arteries were obtained by TEE.

Transesophageal echocardiography may be a useful noninvasive method in the diagnosis of anomalies of the aortic valve.

\section{REFERENCES}

1. Simonds JP: Congenital malformation of the aortic and pulmonary valves. Am J Cardiol 166: 584,1923

2. Herman RL, Cohen IS, Glaser K, Newcomb EW: Diagnosis of incompetent quadricuspid aortic valve by two-dimensional echocardiography. Am J Cardiol 53: 972, 1984

3. Matsui K, Kohno H, Fukuyama T: Quadricuspid aortic valve: Report of a case associated with severe aortic regurgitation and review of the literature. Jpn J Surg 19: 93, 1989

4. Hurwitz LE, Roberts WC: Quadricuspid semilunar valves. Am J Cardiol 31: 623, 1973

5. Amioka H, Okamoto M, Matsumoto K: Echo and Doppler cardiographic findings of isolated quadricuspid aortic valve: A case report and a review of the literature. J Cardiography 16: 1003,1986

6. Kim HS, McBride RA, Titus JL: Quadricuspid aortic valve and single coronary ostium. Arch Pathol Lab Med 112: 842, 1988

7. Robicsek F, Sanger PW, Daugherty HK, Montgomery CG: Congenital quadricuspid aortic valve with displacement of the left coronary orifice. Am J Cardiol 23: 288, 1969 